\title{
Kebudayaan dan Kapitalisme (Studi Buruh Tenun Pandai Sikek)
}

\author{
Jonson Handrian G
}

\section{A. Pendahuluan}

Pernyataan Marx yang mengatakan bahwa sejarah manusia pada dasarnya adalah sejarah pertentangan kelas ${ }^{1}$, merupakan sumber insprirasi bagi saya untuk melihat berbagai fenomena sosial. Kegigihan Marx untuk mengkritik rezim Kapitalisme bukan tanpa hasil, banyak karya-karya penting lahir dari tangannya. Meskipun Marx mendapatkan kritik dari berbagai arah, namun ide-ide dan gagasan yang dirumuskannya mampu menembus dimensi waktu sampai seabad lebih dan masih relevan untuk menjelaskan realitas saat ini. Pada dasarnya, Ajaran Marx adalah ideologi kelas pekerja, expresi teoritis dari kepentingankepentingan dasarnya; itu merupakan ilmu pengetahuan dari perubahan revolusioner dunia (Stepanova, 2004: 2).

Apabila kita membayangkan uang kertas Rp5.000-, mungkin yang tervisualkan dalam piriran adalah wajah salah satu tokoh pahlawan nasional yang berasal dari Sumatera Barat, yaitu Tuanku Imam Bonjol. Namun, tidak banyak yang tau disisi lain dari uang tersebut adalah gambar aktivitas bertenun masyarakat Pandai Sikek. Pemilihan gambar aktivitas bertenun masyarakat Pandai Sikek pada uang tersebut merupakan apresiasi yang besar dari pemerintah. Secara tidak langsung, pemerintah mengakui eksistensi dari kearifan lokas masyarakat tersebut. Koentjaranigrat (2009: 144) berpendapat bahwa kebudayaan itu pada dasarnya diturunkan melalui proses belajar. Sama seperti kebudayaan, kemahiran bertenun juga melalui proses belajar dan masa yang panjang. Masyakarat Pandai Sikek menganggap kearifan lokal tersebut sebagai "pusako"2 yang harus dijaga dan dilestarikan sampai-sampai muncul sebuah ungkapan buah bibir "malu gadang rasonyo kalau padusi Minang Pandai Sikek ndak bisa batanun" ". Oleh karena itu, kemahiran ini tidak boleh diajarkan kepada orang

\footnotetext{
${ }^{1}$ Lihat Karl Marx and Frederick Engels. 1962. "The Communist Manifesto". Midlesex: Penguin Book.

2 Lihat Ginting,Jonson Handrian. 2014. "Tradisi Bertenun Pada Masyarakat Pandai Sikek. Studi Kasus: Nagari Pandai Sikek, Kecamatan X Koto, Kabupaten Tanah Datar." Skripsi. Padang: Universitas Andalas. HIm 90

${ }^{3}$ Artinya: "malu berat rasanya apabila perempuang Minang Pandai Sikek tidak bisa bertenun".
} 
lain di luar kampung, apalagi di luar wilayah atau suku bangsa Minangkabau ${ }^{4}$ Penjelasan ini terasa sangat romantis dan ideal dalam konteks integrasi unsur-unsur kebudayaan, tapi secara teknis permasalahan ini sangat kompleks apabila dilihat dari konteks dan sudup pandang lain. Untuk itu, muncul pertanyaan menarik yang penting untuk dijawab, yaitu bagaimanakah bentuk dan fenomena tersebut dilihat dalam kritik kapitalisme dan ekonomi politik ala Marx? Apa dan bagaimanakah peran budaya dalam dunia kapitalisme?

\section{B. Kerangka Konseptual}

Pada bab ini, saya akan memulai pembahasan mengenai konsep komoditas. Marx (1859: 6) berpendapat bahwa komoditas adalah segala sesuatu yang memiliki nilai guna dan nilai tukar (use value and exchange value). Hasil karya bertenun masyarakat Pandai Sikek adalah selendang dan sarung ${ }^{5}$. Dalam hal ini, selendang dan sarung adalah komoditas karena memiliki nilai tukar dan nilai guna. Komoditas ini (Selendang dan sarung) biasanya dipakai disetiap acara atau upacara adat bahkan pada acara-acara yang tidak terkait dengan adat sekalipun. Karena corak selendang dan sarung ini sangat kaya motif dan filosifi, banyak wisatawan luar dan dalam negeri ingin memilikinya. Kisaran harga tenun tersebut sangat beragam mulai dari Rp1.500.000- sampai Rp10.000.000-. harga yang fantastis untuk harga sebuah selendang dan sarung. Pada sistem produksi komoditas ini, kain tenun adalah salah satu bentuk industri rumahan.

Di Pandai Sikek, hampir setiap rumah memiliki panta ${ }^{6}$. Apabila pada sektor industri lain laki-laki lebih diutamakan dan diharapkan dalam perekrutan buruh $^{7}$, pada sektor industri tenun (khususnya di Pandai Sikek) biasanya didominasi oleh perempuan karena pekerjaan ini harus dikerjakan dengan telaten dan sabar. Gagasan bahwa kaum wanita merupakan pekerja inferior secara alamiah susah untuk dibantah (Boserup, 1984: 217). Buruh perempuan yang bekerja sebagai penenun biasanya berumur 25 tahun keatas, anak-anak dibawah 25 tahun biasanya bertenun hanya ketika liburan atau anak yang tidak mengecap pendidikan formal. Dalam sistem pembangian kerja keluarga, biasanya ayak bekerja sebagai petani da ibu

\footnotetext{
${ }^{4}$ Seluruh data mengenai tradisi bertenun pada masyarakat Pandai Sikek diambil dari Skripsi tersebut.

${ }^{5}$ Lebih dikenal dengan istilah songket

${ }^{6}$ Alat utama yang dipakai untuk menenun kain.

${ }^{7}$ lihat
} 
sebagai penenun kain. Pengintegrasian pekerjaan ayah dan ibu dalam formasi keluarga ini bertujuan agar keluarga tersebut tetap survive ${ }^{8}$.

Satu paket kain tenun (terdiri dari sarung dan selendang) dikerjakan oleh satu orang selama kurun waktu satu bulan. Kain tenun yang sudah selesai, diantar kepada induak samang $^{9}$ dan pada saat itu buruh langsung mendapat uang sebesar Rp800.000 sampai Rp1.200.000-. Pada dasarnya, panta dan benang untuk membuat kain tenun tersebut adalah milik buruh sendiri. Namun bagaimanapun juga, buruh tidak bisa menjualkan dan memasarkan kain tenunnya sendiri, ia harus menjual atau mengantarnya kepada induk semang terlebih dahulu karena konsumen akan belanja kain ke toko-toko kain tenun, bukan ke buruh tenun langsung.

Sampai pada titik tertentu, komoditas berupa kain songket atau kain tenun Pandai Sikek adalah barang yang bisa masuk dalam wilayah fetitisme. Fetitisme komoditas adalah pemujaan yang mutlak dan mendalam terhadap setiap objel yang didalamnya disemayami oleh roh atau kekuatan terentu (secara psikologis) sehingga menimbulkan pengaruh "magis" dan daya pesona. ${ }^{10}$ barang ini diburu secara masal. Ada sebuah kesadaran kolektif yang berkembang pada masyarakat Minangkabau, bawa setiap keluarga (terutama wanita) harus memiliki kain songket ${ }^{11}$. Secara tidak langsung, komoditas ini adalah barang yang “didewakan" serta dielu-elukan masyarakat. Realitas ini tentu memberikan gambaran bahwa kain songket memiliki nilai yang tinggi di mata masyarakat.

Dari paparan diatas, rasanya tangan sangat gatal untuk membedah fenomena diatas dengan konsep dan ide gagasan Marx terkati politik ekonomi kapitalisme. Marx menjelaskan (1849: 14-15), di dalam sistem kapitalisme pasar, terminologi yang mempengaruhi harga tenaga kerja adalah jumlah nilai semua komoditas yang perlu dibeli oleh buruh agar ia dapat hidup, artinya agar ia dapat memulihkan tenaga kerjanya serta memperbaruinya dan menggantikannya jika ia sudah tidak dapat bekerja lagi. Dengan kata lain, nilai tenaga kerja buruh adalah jumlah nilai makanan, pakaian, tempat tinggal, dan semua kebutuhan hidup lain si buruh dan keluarganya sesuai dengan tingkat sosial dan kultural masyarakat yang bersangkutan.

\footnotetext{
${ }^{8}$ Lihat Peter Elias. "Family Formation, Occupational Mobility and Part Time Work". Dalam Audrey Hunt. 1988.

"Women and Paid Worker". London: Macmillan Press. HIm 83

${ }^{9}$ Induk semang.

${ }^{10}$ Lihat Marx, Karl. 1887. "Capital : A Critique of Political Economy, Volume I". Moscow: Progress Publishers.

HIm 44

${ }^{11}$ Ginting. Op.Cit. hlm 85
} 
Penjelasan konsep Marx mengenai determinasi upah buruh diatas tentu mengindikasikan bahwa upah Rp800.000 sampai Rp1.200.000 yang diberikan kepada buruh tenun di Pandai Sikek merupakan bentuk exploitasi buruh. sedangkan harga dari komoditas tersebut melampaui harga kerja buruh sampai pada titik 500\%. ketika harga buruh dianggap sebagai komoditas dimana harganya ditentukan oleh hukum permintaan dan penawaran. Bagaimana mungkin seseorang buruh atau pekerja mampu memenuhi kehidupanya beserta keluarga hanya dengan upah paling besar Rp1.200.000-, jangankan untuk kehidupan keluarga, untuk kehidupannya sendiri saja mungkin tidak terpenuhi, bahkan jumlah tersebut masih dibawah UMR di kota tersebut saat waktu penelitian berlangsung Oleh karena itu, bentuk relasi sosial yang dibangun antara induk semang dan buruh adalah relasi yang eksploitasi. Seharusnya, buruh tenun dibayar lebih dari itu. Untuk modal benang saja, buruh mengeluarkan modal sebesar Rp400.000-. artinya, apabila buruh diupah Rp1.200.000, maka upah kreatifitasnya dengan pengerjaan waktu satu bulan hanya dihargai sebesar Rp800.000-. hal ini jelas tidak masuk akal, bagaimana mungkin pekerjaan yang membutuhkan waktu yang sangat lama serta memerlukan skil khusus hanya dibayar bersih Rp800.000. besaran uang tersebut adalah uang yang ia peroleh perbulan karena dalam masa satu bulan hanya satu komoditas yang selesai. Dalam kasus ini, induk semang sebenarnya tidak mengeluarkan beban biaya untuk modal, ia hanya membeli komoditas dari buruh tenun. Dengan kata lain, modal komoditas ini sudah masuk ke dalam bagian dari upah buruh.

Kondi diatas menyebabkan para buruh tenun selalu berada pada posisi yang sangat tidak menguntungkan dan dibelenggu ketergantungan pada belas kasihan induk semang (susilastuti dan handoyo, 1990: 68). Untuk menggambarkan keadaan ini, saya akan mengutip perkataan Tauney, "mereka ibarat orang yang selamanya berdiri terendam dalam air sampai ke leher, sehingga ombak yang kecil sekalipun sudah cukup untuk menenggelamkannya (Scott, 1981:1).

Dalam hal ini, Marx berpendapat bahwa yang dibayarkan oleh induk semang kepada buruh bukanlah sebenar-benar nilai. Nilai yang seharusnya dibayarkan dalam bentuk upah haruslah tidak jauh dari harga jual komoditas tersebut (Oishi, 2001: 145). Apablia harga jual dari komoditas tersebut bisa laku mencapai harga Rp5.000.000-, maka harga yang dibayarkan oleh induk semang kepada buruh harus tidak jauh dari selisih harga tersebut, sekurangkurangnya pertukaran tersebut adalah pertukaran yang ekuivalen. 
Permasalahan ini bukan hanya sampai determinasi jumlah upah, tapi substansinya juga terletak pada nilai buruh. Teori-teori ekonomi klasik termasuk Ricardo melihat keuntungan merupakan selisih dari pemasukan bersih setelah upah buruh dibayar. Ricardo percaya kenaikan atau penurunan upah buruh akan langsung berpengaruh pada keuntungan yang didapatkan. Pemikiran seperti ini yang menurut Marx semakin mempertajam kesenjangan dan ketidak-adilan antara pemilik alat produksi dan buruh. Terlebih dalam sistem kapitalis tak ada buruh yang sukarela menjadi buruh. Buruh menjadi buruh karena dipaksa oleh sistem. Oleh karena itu buruh dan proses kerja buruh juga harus dilihat sebagai komoditas yang juga memiliki nilai. Ketika kapitalis "mengonsumsi" tenaga dan pikiran buruh dalam sebuah proses produksi, saat itulah seorang buruh menghasilkan nilainya. Ada dua nilai yang dimiliki buruh. Pertama adalah conserve value, yaitu nilai dari proses kerja hingga menghasilkan produk. Kedua adalah kemampuan menambah nilai baru yang oleh Marx disebut surplus value $^{12}$.

Surplus value bisa dimaknai sebagai hasil kerja buruh yang sebenarnya nilainya lebih dari upah yang mereka terima. Sehingga menurut Marx seorang buruh harusnya mendapatkan hasil dari kerjanya lebih dari upah yang diterimanya. Hasil lebih yang tidak diterima oleh buruh ini diambil oleh kapitalis untuk dimasukkan ke dalam komoditas dan dipertukarkan untuk akumulasi kapital. Dengan mengambil surplus value dari buruh, sistem kapitalis dapat terus mengakumulasi modal untuk memperbesar produksi dan mendapatkan keuntungan lebih besar lagi secara terus menerus.

Dari penjelasan Marx terlihat bagaimana buruh adalah faktor yang menentukan dalam proses produksi. Tapi kenyataannya, dalam sistem kapitalis, surplus value ini tidak pernah diberikan pada buruh, melainkan terus diambil oleh pemilik modal untuk memperbesar modal dan kapasitas produksi. Jika berpijak dari perspektif Marx ini, maka terlihatlah bahwa sistem kapitalis hanya bentuk eksploitasi terhadap buruh. Kapitalisme semakin mempertajam ketidak-adilan dan kesenjangan antara kelas borjuis dan kelas proletar dan dalam hal ini adalah buruh tenun dengan induk semang.

Marx berpendapat bahwa sistem ekonomi politik kapitalisme akan runtuh dan akan digantikan oleh sistem yang baru. Jelasnya bahwa setiap sistem masyarakat memiliki pola ekonomisnya sendiri, alasan yang dikemukakan adalah bahwa hukum-hukum ekonomi merupakan manifestasi dari hubugan-hubungan sosial yang menentukan cara produksi.

\footnotetext{
${ }^{12}$ Marx. Op.Cit. Das Kapital, V1.hlm 320-321
} 
Dalam perspektif lain, bentuk ekonomi kapitalistis secara dialektis akan menemukan tempanya dalam sejarah, yaitu kehancuran itu sendiri (Ramly, 2004: 151). Namun hal yang menarik pada kasus ini, bentuk eksploitasi buruh ini seakan tidak menemukan titik akhir.

Prinsip dasar pandangan materialisme sejarah Marx pada dasarnya adalah sebuah tesis yang berbunyi “ bukan kesadaran manusia yang menentukan keadaan mereka, tetapi sebaliknya, keadaan sosial lah yang menentukan kesadaran mereka ${ }^{13}$. Tesisnya ini menerangkan bahwa kesadaran akan kesadarannya sebagai kelas bawah atau buruh ditentukan dari keadaan sosialnya. Pada dasarnya, masyarakat Pandai Sikek menyadari akan dirinya beserta kelasnya. Masyarakat tersebut menyadari bahwa mereka memiliki sebuah pusaka tinggi yang mahal dan tidak bisa diajarkan pada orang lain. Masyarakat tersebut juga mengetahui bahwa sistem ekonomi yang dibangun tertait kain songket tersebut tidak menguntungkan buruh dan malah akan memperkaya induk semang, namun perkara ini terkait dengan pusaka tinggi yang menjadi identitas. mau tidak mau, suka suka atau tidak, perempuan-perempuan di pandai sikek harus tetap bertenun. Beberapa buruh tenun memberi keterangan, jika aktivitas ini tidak terkait sama sekali dengan identitas dan kebudayaan, maka mereka sudah berpindah profesi dari buruh tenun ke petani apabila sistem yang dipakai masih tetap seperti ini.

Berbagai regulasi tidak tertulis dalam tradisi bertenun menghambat proses revolusi sistem ekonomi, seperti kesepakan kolek bahwa kreatifitas dan kemahiran ini adalah pusaka dan tidak bisa diajarkan kepada orang lain, tidak boleh membuka toko diluar desa, dll. Berbagai usaha untuk keluar dari sistem ini sudah pernah dilakukan, ada yang pindah induk semang, ada pula yang memilih jalan "keras" dengan mengajarkan cara bertenun kepada orang lain dan membuka toko kain tenun di desa dan kota lain. Namun, beberapa individu yang memilih jalan ini berakhir tragis, rumah mereka dibakar dan dibuang dari adat. Akan tetapi, bisnis kain tenunnya berjalan lancar di tahun pertama sebagai kapitalis baru. Ia memiliki buruh dan profit yang banyak. Pada tahun berikutnya, individu tersebut sakit yang tidak diketahui penyakitnya dan akhirnya wafat. pola ini terjadi ke beberapa orang yang memilih jalan tersebut ${ }^{14}$.

Keadaan ini seakan memberi legitimasi bahwa regulasi yang teridak tertulis tersebut bersifat sangat sakral dan tidak boleh dilanggar, siapa saja yang tidak mengikuti adat akan

\footnotetext{
13 Marx. Op.Cit. hlm 13.

${ }^{14}$ Ginting. Op.Cit. hlm 112.
} 
berakhir tragis. Dalam hal ini kebudayaan berubah menjadi suatu bentuk yang sangat dekat dengan kapitalisme. Kebudayaan menjadi alat untuk melancarkan rezim-rezim kapitalisme dimana induk semang ingin mendapatkan profit sebanyak-banyaknya dan menjadikan kerja buruh tersebut sebagai komoditas.

Dalam pandangan Marx (Suseno, 2000: 145) kebudayaan adalah bagian dari Suprastruckture karena bagian dari tatanan institusional dan tatanan kesadaran kolektif yang lebih dikenal dengan istilah ideologi. tatanan ini mengatur kehidupan bersama masyarakat baik di dalam dan di luar bidang produksi. Untuk memahami pendapat Marx ini, kita perlu melihat bahwa hubungan-hubungan produksi dalam basis (buruh) selalu berupa strukturstruktur kekuasaan, lebih tepatnya struktur-struktur kekuasaan ekonomi.

Apabila dilihat pada perpsektif yang lebih longgar (tentunya tidak pada perspektif serta ide dan gagasan Marx), sistem upah yang berlaku di bidang industri ini mempunyai pengaruh yang besar terhadap hubungan antar warga masyarakat. tukar menukar jasa dengan uang selalu dilaksanakan secara terbuka dan secara tatap muka. Pemberi jasa harus berhubungan langsung dengan pemberi uang mengakibatkan adanya hubungan-hubungan subjektif, terutama individu-individu yang bertransaksi masih kerabat (Tidorante dan Sangke, 1993: 48). 


\section{Kesimpulan}

Pada tulisan ini, saya menjelaskan berbagai fenomena buruh tenun di Pandai Sikek dalam frame dan "kacamata" gagasan Marx. Melihat kompleksnya masalah buruh tenun, maka saya akan menggunakan beberapa konsep penting dari gagasan Marx seperti basis dan bangunan atas, kesadaran kelas, sistem waktu kerja serta upah buruh. penggunaan konsep tersebut untuk melihat bagaimana sebuah aktivitas atau pekerjaan (bertenun) dalam lingkaran kebudayaan menjadi bagian dari rezim kapitalisme. Dalam hal ini kebuayaan berada pada tataran Suprastruckture atau bangunan atas. Sebenarnya perlu dipertanyakan lebih lanjut apakah kebudayaan itu bisa disebut sebagai kapitalisme itu sendiri, namun untuk menjawab itu tentu perlu penelitian yang lebih lama dan mendalam. 


\section{DAFTAR PUSTAKA}

Boserup, Ester. 1984. "Peranan Wanita dalam Perkembangan Ekonomi”. Jakarta: Yayasan Obor Indonesia

E. Stepanova. 2004. “Karl Marx Nabi Kaum Proletar”. Yogyakarta: Mata Angin.

Hunt, Audrey. 1988. "Women and Paid Worker". London: Macmillan Press

Marx, Karl. Frederick Engels. 1962. "The Communist Manifesto". Midlesex: Penguin Book. . 1859. "A Contribution to the Critique of Political Economy". Moscow: Progress

Publishers. . 1849. "Wage-Labor and Capital”. German: Dodo Press.

1887. "Capital : A Critique of Political Economy, Volume I". Moscow: Progress Publishers.

Ginting, Jonson Handrian. 2014. "Tradisi Bertenun Pada Masyarakat Pandai Sikek. Studi Kasus: Nagari Pandai Sikek, Kecamatan X Koto, Kabupaten Tanah Datar." Skripsi. Padang: Universitas Andalas.

Koentjaraningrat. 2009. “Pengantar Ilmu Antropologi”. Jakarta: Rineka Cipta

Magnis-Suseno, Franz. 2000. "Pemikiran Karl Marx dari Sosialisme Utopis ke Perselisihan Revisionisme". Jakarta: Gramedia.

Oishi, Takahisa. 2001. The Unknown Marx: Reconstrukting a Unified Perpsective. London: Pluto Press.

Ramly, Andi Muawiyah. 2004. "Peta Pemikiran Karl Marx: Materialisme Dialektis dan Materialisme Historis”. Yogyakarta: LkiS

Scott, C.James. 1981. “Moral Ekonomi Petani”. Jakarta: LP3ES

Susilastuti, Dewi Haryani. Bambang Wisnu Handoyo. 1990. "Buruh Jahit Di Pedesaan Jawa:Suatu Studi Tentan Kondisi Sosial Ekonomi Dan Strategi Kelangsungan Hidup”. Yogyakarta: Pusat Penelitian Kependudukan Universitas Gadjah Mada.

Tidorante, Usuluddin. Simon Sangke. 1993. "Hubungan Kerja Dan Sistem Upah Tradisional Daerah Sulawesi Tengah”. Departemen Pendidikan Dan Kebudayaan, Direktorat Jendral Kebudayaan, Direktorat Sejarah Dan Nilai Tradisional. Bagian Proyek Penelitian Pengkajian Dan Pembinaan Nilai-Nilai Budaya Sulawesi Tengah. 